\title{
Mathematical and moral disagreement
}

\author{
Silvia Jonas
}

August 16, 2019

\begin{abstract}
The existence of fundamental moral disagreements is a central problem for moral realism and has often been contrasted with an alleged absence of disagreement in mathematics. However, mathematicians do in fact disagree on fundamental questions, for example on which set-theoretic axioms are true, and some philosophers have argued that this increases the plausibility of moral vis-à-vis mathematical realism. I argue that the analogy between mathematical and moral disagreement is not as straightforward as those arguments present it. In particular, I argue that pluralist accounts of mathematics render fundamental mathematical disagreements compatible with mathematical realism in a way in which moral disagreements and moral realism are not 1
\end{abstract}

Keywords: disagreement; mathematical realism; moral realism; set-theoretic pluralism; multiverse; Continuum Hypothesis.

\footnotetext{
${ }^{1}$ Many thanks to Marianna Antonutti, Carolin Antos-Kuby, Claire Benn, Sharon Berry, Christine Bratu, James Brown, Thomas Buchheim, Mark Colyvan, Benedict Eastaugh, Gerhard Ernst, Peter Gerdes, Stephan Hartmann, Jan-Christoph Heilinger, Vera Hoffmann-Kolss, Jessica Isserow, Leora Katz, Christian Kietzmann, Sebastian Köhler, Nicholas Laskowski, Hannes Leitgeb, Toby Meadows, Mark Douglas Warren, Thomas Schmidt, Olla Solomyak, Georgie Statham, Casper Storm Hansen, Marta Sznajder, Christine Tiefensee, Teemu Toppinen, Peter Van Inwagen, Herman Veluwenkamp, Hugh Woodin, Hannes Wortmann, and three anonymous referees for many helpful comments and discussions. Work on this research paper has been supported by the Minerva Foundation and the Max Planck Society.
} 


\section{Realism and disagreement}

Fundamental disagreement $\mathrm{t}^{2}$ is widely thought to be one of the central problems for moral realism $3^{3}$ Mackie, for example, famously argues that 'radical differences between first order moral judgements make it difficult to treat those judgements as apprehensions of objective truths' (Mackie, 1977, p. 36), and similar views have been expressed, or are implicit, in many other arguments against moral realism.4 By contrast, worries about disagreement never come up in discussions about mathematical realism. There, ontological debates revolve around the question of epistemic access 5 , the referential and quantificational indeterminacy of mathematical objects (understood as sets) ${ }^{6}$ and the (in)dispensability of mathematical objects to our

\footnotetext{
${ }^{2}$ Not every kind of disagreement is considered problematic for realist views of morality. For example, disagreements due to a lack of information, false evidence, or cognitive shortcomings are generally considered unproblematic because such disagreements can be 'explained away': had Mary not been on drugs, she would not have disagreed with Peter on the issue of capital punishment; had Peter known the error rate in capital cases, he would not have defended the legitimacy of capital punishment; and so on. Likewise, disagreements that can be shown to be merely verbal, such that there is in fact no single proposition which is accepted by one person and rejected by the other, are not considered problematic: 'if we think that capital punishment should be abolished, $a$ disagrees with us only if there is a sentence $s$ in $a$ 's idiolect such that $a$ rejects $s$, and the content of $s$ is correctly given by our sentence "Capital punishment should be abolished"' (Tersman, 2006, p. 25). The kinds of disagreement that are thought to pose a problem for moral realists are thus disagreements between epistemic peers that are genuine in the sense of being not merely verbal, and that appear persistently resistant to rational resolution even under ideal epistemic circumstances. It is the latter kind of disagreement I shall henceforth refer to as 'fundamental disagreement'. Cf. Gowans (2000) for a historical survey of the problem of disagreement and Tersman (2006) for a discussion of different kinds of moral disagreement.

${ }^{3}$ The 'problem of disagreement' in fact comprises a variety of different antirealist arguments that start with a premise from moral disagreement and conclude with a rejection of moral realism. Enoch (2009), Loeb (1998), and Tersman (2006) provide extensive discussions of these different versions (Loeb and Tersman arguing that one particular interpretation of the problem of disagreement constitutes a decisive refutation of moral realism, Enoch denying that there is any way of spelling out the problem of disagreement in such a way that it poses a threat to moral realism). What I say in this paper applies to all versions of such arguments (to the extent, of course, that they feature a comparison with mathematics).

${ }^{4}$ Proponents of the view that disagreement undermines moral realism include Burgess (2007); Loeb (1998); Mackie (1977); Sturgeon (1984, 2006); Tersman (2006); Williams (1985); Wong (1984). Opponents of this view include Brink (1989); Enoch (2009, 2011); Gewirth (1988); Nagel (1986); Nussbaum (1993); Rawls (1980); Shafer-Landau (1994). For an overview over the most important positions in the debate, see Gowans (2000).

${ }^{5}$ Cf., for example, Benacerraf (1973); Field (1989).

${ }^{6}$ Cf., for example, Benacerraf $(\overline{1965)}$; Hellman (1989).
} 
best physical theories 7 How come mathematical realists have not had to defend themselves against worries about disagreement?

A likely answer is that mathematics is widely perceived as an unanimous, disagreementfree domain, or at least as a domain where 'the apparent difference in the scope and nature of the disagreement' (Enoch, 2011, p. 188) distinguishes it clearly from the domain of ethics. Brian Leiter summarizes this view as follows:

'[P] ersistent disagreement on foundational questions. . . distinguishes moral theory from inquiry in... mathematics... [T] here exists a remarkable crosscultural consensus among theorists about... mathematical truths, while moral philosophers... find no common ground on foundational principles.' (Leiter, 2009, pp. 8 and 16)

As a result, mathematical realism is typically not charged with objections from disagreement. Thus, mathematical realists are often thought to have a much better case than moral realists (at least regarding the problem of disagreement). Call this the 'Standard View.'

The problem with the Standard View is that mathematics is in fact far from disagreement-free. In the following section, I briefly explain some of the most important fundamental disagreements in current foundational mathematics, and I will explain their metaphysical import. In section 3, I discuss three recent arguments by moral realists that draw on an analogy between mathematical and moral disagreements in order to support moral realism. In section 4, I refer to recent work on mathematical pluralism in order to argue that those analogies do not hold because mathematical and moral disagreement are relevantly disanalogous. In section 5, I address three potential objections to my argument. In section 6 , I conclude that fundamental mathematical disagreements are compatible with mathematical realism in a way in which moral disagreements and moral realism are not.

\footnotetext{
${ }^{7}$ Cf., for example, Colyvan (2001); Field (1980); Putnam (1975); Quine (1951).
} 


\section{Fundamental mathematical disagreements}

\subsection{The logical rules}

The first and perhaps most fundamental disagreement between mathematicians concerns the rules of logic. While it is true that classical propositional and first-order logic: 8 dominate actual practice, it is also true that other logics have important applications in different contexts. For example, propositional logic investigates the validity of certain forms of reasoning, whereas predicate logic can illuminate also other inference patterns; paraconsistent logics offer a more discriminating way of dealing with inconsistencies than logics based on the principle of explosion; etc.

One of the most notorious examples for disagreements about logic concerns (nonclassical) intuitionistic logic. Intuitionistic logic plays a central role in the constructive parts of mathematics and computer science. Moreover, some hold that intuitionistic logic may be the most appropriate system to deal with the indefinitely extensible hierarchy of sets and its implied notion of potential infinity $!^{9}$ and some even believe that intuitionistic logic is the uniquely correct logic for mathematics ${ }^{10}$ Intuitionistic logics famously involve the rejection of the 'law of excluded middle' $(\mathrm{LEM})^{11}$ as well as related principles such as the 'law of double negation', existence proofs by reductio ad absurdum, asf. So on the face of it, the disagreement between the intuitionist and the classical mathematician is over the question which rules of logic are correct, and consequently, over what counts as a theorem

\footnotetext{
${ }^{8}$ That is, logical systems based on the laws of excluded middle and non-contradiction plus monotonic entailment, commutativity of conjunction, and DeMorgan duality.

${ }^{9} \mathrm{Cf}$. Linnebo and Shapiro (2019).

${ }^{10} \mathrm{Cf}$. Van Atten et al. (2002); Van Atten (2006).

${ }^{11}$ It should be stressed that, although intuitionists shun the use of LEM in proofs, $\neg \neg L E M$ is nevertheless a theorem of intuitionistic logic. Thus, being an intuitionists does not amount to an affirmation of $\neg L E M$.

${ }^{12}$ The most famous example for a classically invalid intuitionistic theorem is Brouwer's Continuity Theorem, which states that every function defined on the closed interval $[0,1]$ of the continuum is uniformly continuous. Cf. Brouwer (1967).
} 
However, one might object that the controversy between classical and intuitionistic mathematicians is only apparent. After all, logical terms in their intuitionistic use have a very different meaning from their classical counterparts: while the classicist provides 'truth-conditions' for logical statements, the intuitionist offers 'proofconditions' that explain when a mathematical construction counts as a proof of a complex statement. On this reading, c proves ' $\mathrm{p} \vee \mathrm{q}$ ' iff c proves $\mathrm{p}$ or c proves $\mathrm{q}$; c proves ' $\mathrm{p} \rightarrow \mathrm{q}$ ' iff $\mathrm{c}$ is a function that converts any proof of $\mathrm{p}$ into a proof of $\mathrm{q}$; $\mathrm{c}$ proves ' $\neg p$ ' iff c proves ' $\mathrm{p} \rightarrow 0=1$ '; asf.

Given these meanings, no classicist would wish to affirm 'p or $\neg p$ ' as a general logical principle, for, when spelled out, it asserts that every (mathematical) proposition is decidable! Similarly, considering that existential quantification is explained as a generalization of 'or,' so that a proof of ' $\exists x \phi$ ' provides a method of finding an instance together with a (constructive) proof that it satisfies $\phi$, no classicist would apply the method of reductio to establish such 'existence' (Hellman and Bell, 2006. p. 64).

Considering these differences in meaning, the intuitionistic and the classical readings of LEM could be argued to be completely different laws ${ }^{13}$ If this were the case, then the disagreement between proponents of each reading would be merely apparent ${ }^{14}$ and perhaps better described, not as a disagreement over logical laws, but as a disagreement over the meaningfulness of assertions implying determinate truthvalues for statements of infinitistic mathematics.

However, radical intuitionists, who endorse a verificationist theory of meaning, insist that mathematical reasoning along classical lines is illegitimate or even unin-

\footnotetext{
${ }^{13} \mathrm{Cf}$. Hellman (1989) for a detailed discussion of the communication problem between intuitionistic and classical mathematics.

${ }^{14}$ Indeed, moderate constructivist frameworks like Bishop (1967) reject any non-classical principles, such as Brouwer's Continuity Theorem, and thus generate no conflict with classical mathematics.
} 
telligible, and hence, that core mathematical principles based on such reasoning - for example the principle of classic analysis that any bounded set of real numbers has a

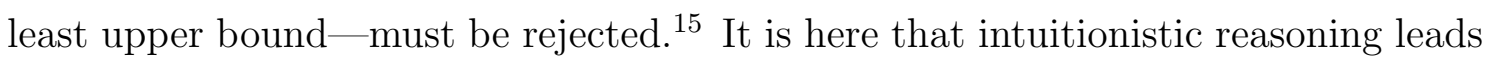
to a clear disagreement with classical mathematics.

\subsection{The axioms of set theory}

The second class of fundamental mathematical disagreements concerns the axioms of set theory. Since all mathematical objects can be construed as sets, and all mathematical theorems deduced in first-order logic from the now standard ZermeloFraenkel (ZF) axioms, set theory is widely considered the ultimate foundation of mathematics. However, set theory grapples with two kinds of fundamental disagreement.

\subsubsection{Disagreements over axioms of ZFC}

The first one are disagreements over some of the axioms of Zermelo-Frankel set theory with Choice (ZFC). Take for example $e^{16}$ the Axiom of Regularity $\forall S(S \neq \emptyset \rightarrow$ $(\exists x \in S) S \cap x=\emptyset)$, which states that every non-empty set contains an element that is disjoint from $\mathrm{S}$, so that the relation $\in$ on any family of sets is well-founded. Among other things, this axiom implies the impossibility of infinitely descending sequences (such as $x_{0} \ni x_{1} \ni x_{2} \ni \ldots$ ), sets that are members of themselves $(x \in x)$, and cyclical chains of membership ( $\operatorname{such}$ as $x_{0} \in x_{1} \in x_{2} \ldots x_{n} \in x_{0}$ ). Regularity thus restricts the concept of set in a particular way, which, for some mathematicians, corresponds exactly to their intuitions about what kinds of objects sets are. George Boolos, for example, thinks that Regularity gets things right because non-well-founded sets

\footnotetext{
${ }^{15}$ Hermann Weyl (1994) rejects this principle.

${ }^{16}$ To keep my argument concise, I mention only one debate here. However, there has also been significant controversy over the axioms of Choice and Power Set, as well as the axiom schema of Replacement.
} 
would be 'pathological' (Boolos, 1971, p. 220), and Abraham Fraenkel, Yehoshua Bar-Hillel, and Azriel Levy feel that 'no field of set theory or mathematics is in any general need of sets which are not well-founded' (Fraenkel et al., 1973, p. 88). To others, however, accepting Regularity is counter-intuitive. Peter Aczel, for example, objects that Regularity prevents us from 'considering exciting new ideas and intuitions that are in need of suitable mathematical expression' (Aczel, 1988, p. xix), notably in the contexts of process algebra and non-standard analysis. Similarly, Adam Rieger worries that 'ZF [with Regularity] restricts the notion of set more than the paradoxes demand' (Rieger, 2008, p. 175). The disagreement here runs just as deep as the most fundamental philosophical disagreement: what is at stake is nothing less than the ultimate nature of sets.

\subsubsection{Disagreements over additions to ZFC}

The second kind of disagreement emerges over the question whether set theory needs new axioms (and if so, which?) in order to settle statements that are independent of ZFC, i.e. whose affirmation and negation are both consistent with ZFC.

The most notorious independent statement is, of course, Cantor's Continuum Hypothesis $(\mathrm{CH})$, which asserts that there are no cardinalities that are strictly larger than that of the natural numbers $\left(\aleph_{0}\right)$ but strictly smaller than that of the reals $\left(2^{\aleph_{0}}\right){ }^{17}$ In 1938, Kurt Gödel (1938) developed the method of inner models and defined a minimal inner model $L$ of the universe of sets $V$. He then showed that CH holds in $L$, and consequently, that CH cannot be disproved from ZFC. In 1963, Paul Cohen (1963) invented the method of forcing and defined a model $V^{\mathbb{B}}$ of the universe of sets given a complete Boolean algebra. He then showed that $\neg C H$ holds

\footnotetext{
${ }^{17}$ The Continuum Hypothesis is the most famous independent statement, but there are many more questions that cannot be answered in ZFC, almost all of them about the structure of uncountable sets, for example whether Martin's axiom is true; whether inaccessible/ Mahlo/ supercompact/ huge etc. cardinals exist; whether the Normal Moore Space conjecture is true; whether all Whitehead groups are free; whether all projective point-sets are Lebesgue-measurable; etc.
} 
in $V^{\mathbb{B}}$, and consequently, that $\mathrm{CH}$ cannot be proved from ZFC. Together, Gödel's and Cohen's results show that $\mathrm{CH}$ is independent of $\mathrm{ZFC}$, and consequently, that ZFC cannot settle the question whether the reals are the second-largest infinite set.

Some mathematicians, for example Gödel, Cohen, and Hugh Woodin, believe that undecidable statements like $\mathrm{CH}$ have definite truth-values and that it is the task of the mathematician to uncover and prove them. Gödel and Cohen (both of whom suspected that $\mathrm{CH}$ is false) jointly managed to prove the independence of $\mathrm{CH}$ from ZFC, but didn't find a new axiom that would decide CH. Woodin, however, who (since 2010) suspects that $\mathrm{CH}$ is true, is currently in the proces: ${ }^{18}$ of trying to prove a conjecture he termed ' $V=$ ultimate $L$ ', according to which there exists an inner model ('ultimate $L$ ') of the universe of sets $V$ that includes supercompacts and therefore, all large cardinals ${ }^{19}$ If ' $\mathrm{V}=$ ultimate $\mathrm{L}$ ' will turn out to be true, then this will not only prove the existence of the inner model 'ultimate L' for all sizes of infinity (even as yet unknown ones) and paint an orderly, elegant, and manageable picture of the infinite hierarchy of sets. It will also decide a number of undecidable statements, most notably $\mathrm{CH}$, which will come out true.

However, set theorists like Stevo Todorcevie ${ }^{20}$ and Justin Moor ${ }^{21}$ object to the restriction of the set-theoretic universe implicit in ' $\mathrm{V}=$ ultimate L'. They favour forcing, the method originally conceived of by Cohen (1963). Intuitively, this method expands the universe of sets $V$ in all possible directions in order to settle open questions of consistency and independence in a new, bigger universe $V^{*}$. This technique has been shown to be extremely powerful in deciding undecidable statements. For

\footnotetext{
${ }^{18}$ Cf., for example, Woodin (2017).

${ }^{19}$ In his (2010), Woodin shows that an inner model that reaches the level of supercompact cardinalities will encompass all large cardinals, including the ones bigger than supercompacts. Before the publication of Woodin's paper, the construction of an inner model $L$ for $V$ had seemed somewhat hopeless, given that for each type of large cardinal, an entirely new method of construction was necessary - and the hierarchy of large cardinals extends infinitely.

${ }^{20} \mathrm{Cf}$., for example, Todorcevic (2002, 2018)

${ }^{21}$ Cf., for example, Moore (2013)
} 
example, 'Martin's maximum' 22 the strongest possible forcing axiom, posits a larger class of real numbers than the class of real numbers of $\mathrm{V}$, so that the real numbers defined in ZFC constitute only a subset of the reals. Hence, Martin's maximum implies that $\mathrm{CH}$ is false. ${ }^{23}$ which is part of the reason why it is often considered the most serious contender for ' $\mathrm{V}=$ ultimate $\mathrm{L}$ '.

The disagreement between those who see forcing and inner model constructions as giving us a selection of equally good choices for set theory, and those like Woodin looking to find a particularly well understood structure to identify as V, can thus not be reduced to a disagreement about the best way to prove set-theoretic conjectures, and not even to a disagreement about the truth-value of undecidable statements like $\mathrm{CH}$. It is a disagreement about how we should understand some of the most fundamental notions of mathematics, i.e. the notions of set, set-membership, and infinity. This shows, again, that the widespread conception of mathematics as a disagreement-free domain is untenable. An often quoted passage from Hellman and Bell summarizes the situation perfectly:

'Contrary to the popular (mis)conception of mathematics as a cut-anddried body of universally agreed-on truths and methods, as soon as one examines the foundations of mathematics, one encounters divergences of viewpoint and failures of communication that can easily remind one of religious, schismatic controversy.' (Hellman and Bell, 2006, p. 64)

\section{Mathematical disagreement and moral realism}

It is an interesting fact that there do indeed exist genuine, first-order disagreements between mathematicians over some of the most foundational principles in

\footnotetext{
${ }^{22}$ Foreman et al. $(1988)$

${ }^{23}$ Not all forcing axioms imply $\neg C H$, of course. Given any initial universe $\mathrm{V}$, one can find a forcing extension $V_{C H}$ in which $\mathrm{CH}$ is true and $V_{\neg C H}$ in which it is false.
} 
mathematics. However, even more interesting are the ways in which references to mathematical disagreements have recently featured in the meta-ethical literature. In the following section, I outline three ways in which the premise that there exists fundamental mathematical disagreement has been used in arguments for moral realism. ${ }^{24}$ In section 4, I argue that these arguments fail because they rely on an analogy between mathematical and moral disagreement that is ultimately untenable.

\subsection{Cognitive shortcomings}

The most straightforward way to support moral realism with an argument from mathematical disagreement has been offered by David Enoch 2009, p. 42; 2011, p. 211):

1. Faced with an arithmetical disagreement between two subjects $A$ and $B$, we assume a mistake or cognitive shortcoming of some sort on the part of $A$ or $B$.

2. We assume a mistake or cognitive shortcoming of some sort because most of us have a prior commitment to (some version of) realism about arithmetic.25

3. But then also the moral realists may legitimately assume a mistake/cognitive shortcoming in the face of moral disagreement.

\footnotetext{
${ }^{24}$ Note that my reconstructions of Enoch's and Clarke-Doane's arguments are informal presentations of the main lines of thought.

${ }^{25}$ Enoch speaks of 'realism about arithmetic' rather than mathematical realism, so it is unclear if his argument about having a pre-theoretic commitment to realism extends to all of mathematics. If it doesn't, then his argument that we may assume a mistake in the face of moral disagreement just like we assume a mistake in the face of mathematical disagreement is severely weakened, given that it would no longer apply as soon as we consider cases of disagreements involving, say, the real numbers. Thus, it is more likely that he is committed to a stronger reading of his argument, according to which we have a prior commitment to realism about all mathematics, and that this is the reason why people start looking for a mistake when faced with a mathematical disagreement, rather than giving up realism about mathematics. This would also be more plausible overall, for if someone's commitment to realism about all of number theory was what convinced them that either $A$ or $B$ must have made a mistake, then this should apply equally well to cases where they are disagreeing over, say, the twin prime conjecture or the Continuum Hypothesis.
} 
4. Moral disagreement does not amount to evidence that moral realism is false.

Enoch thus defends moral realism against the objection that moral disagreement undermines moral realism. His point is straightforward:

After all, there are many crazy, yet internally consistent, views in physics, mathematics, philosophy, and so on, and this fact may be important in many ways, but it is hard to take it as refuting realism about any of these discourses 2009 , p. 40;2011, p. 209) 26

In other words, instead of thinking of disagreements as a problem, moral realists, just like mathematical realists, should simply consider them the results of a mistake or cognitive shortcoming of some sort. And the fact that people make mistakes surely doesn't threaten moral realism.

This argument involves two key claims: (a) that there exists fundamental disagreement between mathematicians, and (b) that mathematical realism implies the view that mathematical disagreements suggest a mistake on the part of at least one of the disagreeing parties. That (a) is true was established in the first part of this paper; in section 4, however, I will argue that (b) must be rejected. But before that, let's take a look at two more arguments that use a premise from mathematical disagreement to support moral realism.

\subsection{A priori justification}

Another way in which a premise from mathematical disagreement can be employed to support moral realism is by using it to undermine the allegedly privileged status of mathematical beliefs over moral beliefs. Justin Clarke-Doane (2014) believes

\footnotetext{
${ }^{26}$ Enoch's point in the quoted text is that, for arguments using a premise from possible rational disagreement to work, mere internal consistency must be too low a bar for rationality. His reference to 'crazy but consistent' views suggests that by 'crazy' he means views that intuitively seem less than fully rational.
} 
that the existence of fundamental mathematical disagreements weakens epistemically motivated arguments against moral realism. He argues as follows:

1. Many consider mathematical propositions self-evident (provided sufficient mathematical competence) ${ }^{27}$

2. Belief in self-evident propositions is a priori justified; thus, mathematical beliefs are a priori justified.

3. Many consider moral propositions not self-evident because people disagree fundamentally on moral matters, and there cannot be disagreement on what is self-evident.

4. If it is the case that belief in non-self-evident propositions is not a priori justified, then moral beliefs are not a priori justified.

5. However, also mathematicians disagree fundamentally on mathematical matters ${ }^{28}$ so if it is the case that belief in non-self-evident propositions is not a priori justified, then mathematical beliefs are not a priori justified either ${ }^{29}$

6. Mathematical beliefs have no epistemically privileged status over moral beliefs.

The upshot of this argument is that, concerning epistemically motivated arguments, moral realism is no worse off than mathematical realism. It involves two

\footnotetext{
27 '[I]n mathematics, unlike morality, certain sets of propositions are thought to possess a privileged status. Mathematical "axioms," it is commonly said, are also axioms in something like Descartes' sense. They are self-evident. Thus, proving that $\mathrm{p}$ follows from the mathematical axioms is tantamount to proving that $p$ is true. By contrast, there is no set of moral propositions that enjoys such a privileged status' (Clarke-Doane, 2014, p. 239).

28'Indeed, for core claims in every area of mathematics - from set theory to analysis to arithmetic - there are some non-error theorists who deny those claims.' (Clarke-Doane, 2014, p. 241); his emphasis.

29،[M]athematical propositions do not seem to be "provable" or "self-evident" in any interesting sense in which moral propositions do not. This suggests that our mathematical beliefs have no better claim to being at least defeasibly a priori justified than our moral beliefs.' (Clarke-Doane, 2014 , p. 244)
} 
claims: (a) that there exists fundamental disagreement between mathematicians, and (c) that fundamental disagreement between conceptually competent people over a mathematical proposition $m$ is incompatible with an a priori justification of belief in $m$. I established that (a) is true in section 2 ; (c), however, must be rejected. Before I explain why in section 4, let us look at one further argument for moral realism that features a premise from mathematical disagreement.

\subsection{Evolutionary debunking}

A third way in which mathematical disagreement has featured in arguments supporting moral realism is by showing that mathematical realism is a 'companion-in-guilt' with regard to Evolutionary Debunking Arguments (EDAs). EDAs are powerful arguments used by moral antirealists to undermine moral realism. They invoke two distinct problems for moral realism that arise on the assumption that there exist mind-independent moral truths: a problem of epistemic access, and a problem of dispensability. EDAs are usually structured along the following lines:

1. Empirical data from evolutionary biology and psychology suggests that people who believe in objective moral truths have an evolutionary advantage.

2. On the assumption that evolutionary forces are indifferent to moral truth, it seems impossible to explain how evolutionarily determined beliefs could track mind-independent moral truths. (Problem of epistemic access)

3. Disagreement among conceptually competent people ${ }^{30}$ with respect to a moral proposition 'e' affords defeasible evidence that it is intelligible to imagine both that e holds and that not-e holds, i.e. that the moral truths might be very

\footnotetext{
${ }^{30}$ The argument can be made even stronger by replacing 'conceptually competent people' with 'experts'.
} 
different from what we think they are (Clarke-Doane, 2012, p. 335) 31

4. Given their evolutionary benefits, we would hold our moral beliefs even if the moral truths were different from what we think they are, or if there were no moral truths at all. (Problem of dispensability) 32

5. This undermines our reasons to think that moral beliefs correspond to objective, mind-independent moral truths.

6. Moral realism is false 33

EDAs against moral realism are hotly debated, especially since their empirical underpinnings seem to lend them considerable force. One (potentially long-winded and inconclusive) way to counter them would be to argue with the empirical evidence. Another, more efficient way would be to show that accepting EDAs has unacceptable consequences for domains other than ethics. For example, if it could be shown that EDAs do not only discredit moral realism, but also mathematical realism, this could be argued to count heavier against EDAs than against the existence of objective mathematical truths ${ }^{34}$ But is it possible to construct an argument against mathematical realism that is relevantly analogous to EDAs against moral realism?

\footnotetext{
${ }^{31}$ Note that canonical formulations of EDAs as offered by Street (1994) and Joyce (2007) do not depend on a premise from disagreement but on a premise from belief-convergence.

${ }^{32}$ Gilbert Harman famously formulates a dispensability problem that does not rely on evolutionary considerations: 'In explaining the observations that support a physical theory, scientists typically appeal to mathematical principles. On the other hand, one never seems to need to appeal in this way to moral principles. Since an observation is evidence for what best explains it... there is indirect observational evidence for mathematics. There does not seem to be observational evidence... for basic moral principles.' (Harman, 1977, pp. 9f)

${ }^{33} \mathrm{Cf}$. Street (1994); Joyce (2007)

${ }^{34}$ Just like the causal theory of knowledge offered by Goldman (1967) never gained wide acceptance because it implies the impossibility of explaining mathematical knowledge; cf. Colyvan (2001, Ch. 3), Lewis (1986, p. 109), Maddy (1996); Steiner (1975). What is often not mentioned is that Goldman himself explicitly states that his account cannot account for mathematical knowledge.
} 
Clarke-Doane thinks it is. In his $(2012)$, he argues that there is no epistemological ground on which to reject moral realism while endorsing mathematical realism. The key move in his argument involves a premise from mathematical disagreement:

1. People with mathematical beliefs roughly like ours have an evolutionary advantage because those beliefs correspond to first-order logical truths about our physical environment (Clarke-Doane, 2012, pp. 330-332).

2. On the assumption that evolutionary forces are indifferent to truth, it seems impossible to explain how evolutionarily determined beliefs could track mindindependent mathematical truths. (Problem of epistemic access)

3. Disagreement among conceptually competent people with respect to a mathematical proposition $m$ affords defeasible evidence that it is intelligible to imagine both that $m$ and that $\neg m$, i.e. that the mathematical truths very different from what we think they are (Clarke-Doane, 2012, p. 338) ${ }^{35}$

4. Given their evolutionary benefits, we would hold those mathematical beliefs even if the mathematical truths were different from what we think they are, or if there were no mathematical truths at all. (Problem of dispensability)

5. This undermines our reasons to think that mathematical beliefs correspond to mind-independent mathematical truths.

6. Mathematical realism is false.

Clarke-Doane's conclusion is that, given that both moral and mathematical realism are vulnerable to arguments from evolutionary debunking, there may be no

\footnotetext{
${ }^{35}$ 'There have been notorious disagreements _ disagreements that do not result from disagreements over whether there are any (substantive) mathematical truths at all-surrounding the standard axioms of all of our mathematical theories, from recondite axioms of higher set theory, to the characteristic axiom of the calculus, to such apparent trivialities of arithmetic as that every natural number has a successor' (Clarke-Doane, 2012, p. 336).
} 
epistemological ground on which to be a moral antirealist and a mathematical realist 36

His argument involves two claims: (a) that there exist fundamental disagreements between mathematicians, and (d) that such disagreements are evidence that the mathematical truths could be very different from what we believe them to be. As mentioned above, (a) is true; as will be argued, however, (d) must be rejected ${ }^{37}$ To sum up: in this section, I demonstrated how moral realists have used a premise from mathematical disagreement in order to support moral realism, and that their arguments involve not only the (true) claim (a) that there exists fundamental mathematical disagreement, but in each case an additional claim about this disagreement which I have indicated is false. These additional claims are:

(b) Mathematical realism implies the view that disagreements between two subjects $A$ and $B$ about a mathematical proposition $m$ suggest that either $A$ or $B$ (or both) must be mistaken.

(c) Fundamental disagreement between conceptually competent people over a mathematical proposition $m$ is incompatible with an a priori justification of belief in $m$.

(d) Mathematical disagreements are evidence that the mathematical truths could be very different from what we believe them to be.

\footnotetext{
${ }^{36}$ I would go even one step further: if EDAs could really be shown to undermine not only moral, but also mathematical realism, then this would be a reason to reject EDAs, not mathematical realism. It is not clear to me that EDAs against mathematical realism work, but if they did, then this might count heavier against EDAs than against mathematical realism.

${ }^{37}$ In footnote 13 of his (2012), Clarke-Doane rules out as 'irrelevant' complications arising from pluralist views like Balaguer (1995, 1998a), 'according to which the [mathematical] universe is rich enough, and the semantics of [mathematical] discourse cooperative enough, that any "intuitively consistent" [mathematical] theory is automatically about the segment of the [mathematical] universe of which it is true (and there is always such a segment).' However, these complications are far from irrelevant. In section 4, I discuss the meta-ethical relevance of pluralist views of mathematics for arguments like Clarke-Doane's.
} 
In the following, I will argue that mathematical and moral disagreement are disanalogous in a way that falsifies these three additional claims, and hence, that the existence of mathematical disagreement cannot be used to support moral realism in the ways discussed above.

\section{Realism and mathematical pluralism}

Meta-ethicists have argued that the existence of fundamental mathematical disagreements increases the plausibility of moral vis-à-vis mathematical realism. The goal of this paper is to show that the analogy between mathematical and moral disagreement is not as straightforward as those arguments present it because mathematical disagreements are compatible with mathematical realism in a way in which moral disagreements and moral realism are not. In the following, I illustrate how it is possible, both from a mathematical and from a philosophical point of view, to accommodate a plurality of mathematical realms within a realist conception of mathematics. Thus, apparently first-order mathematical disagreements can be reduced to (aesthetic or pragmatic) disagreements about which parts of mathematical reality are most pertinent to study. I conclude that such a view is not available to the moral realist, and hence, that the existence of mathematical disagreement cannot be used to support moral realism in the ways discussed above.

\subsection{A set-theoretic multiverse}

Practising mathematicians do not typically concern themselves explicitly with philosophical questions about epistemic access or the nature of mathematical entities. They get on with their mathematical work, and that's that. However, philosophical questions sneak into mathematical practice. For example, open questions like $\mathrm{CH}$ force mathematicians to take a stand on the question whether all mathemati- 
cal propositions have determinate truth-values. Philosophical intuitions about this question will then set the directions for further mathematical research. For instance, the fact that Woodin is spending so much time and effort trying to prove 'V=ultimate L' suggests a belief in a best way of modelling the set-theoretic universe, a best way to understand infinity, and consequently, a uniquely right answer to $\mathrm{CH}$.

There are others, however, like Feferman et al. (2000) or Hamkins (2012) for whom it is not at all clear that all mathematical propositions have determinate truth-values. In particular, it is not clear that there is an absolute background concept of set, with a corresponding absolute set-theoretic universe in which every set-theoretic question has a definite answer. In his (2012), Hamkins argues for what he calls a 'multiverse' view of mathematical reality. According to this view, there is an 'enormous range of set-theoretic possibilities' (Hamkins, 2012, p. 416), or more precisely, many subtly distinct concepts of set, each instantiated in a corresponding set-theoretic universe that exists 'independently in the same Platonic sense that proponents of the [single set-theoretic] universe view regard their universe to exist' (Hamkins, 2012, p. 417), and each exhibiting diverse set-theoretic truths. The set-theoretic 'multiverse' is comprised by the totality of these different set-theoretic universes. In some of them, controversial mathematical propositions like $\mathrm{CH}$ are true, and in some of them they are false. However, given that we have a very good understanding (Hamkins speaks of 'experience') of the conditions under which propositions with indeterminate truth-values like $\mathrm{CH}$ do and do not hold in a universe, it is not the case that such propositions are obviously true nor false. Hence, mathematical reality is not characterised by an absolute conception of its most fundamental entities, i.e. sets, but branches out into a multitude of different universes, each evolving out of slightly different ways of 'precisifying' the 
concept of set ${ }^{38}$ This way of looking at mathematical reality renders the search for classical solutions (in the form of new axioms) to hitherto unresolved fundamental issues moot: mathematicians can legitimately explore all the different, 'mutually exclusive' parts of mathematical reality they want, without needing to worry about which of those parts constitutes 'the truth.' Mathematical 'disagreements' should thus not be understood as fully-fledged first-order disagreements, but rather, as aesthetic or pragmatic disagreements about which parts of mathematical reality are most beautiful, or most useful to explore.

\subsection{Plenitudinous Platonism}

Similar ideas can be found also in the philosophy of mathematics. The central idea of Balaguer's 'Full-blooded Platonism' (FBP), for example, is to assume a 'plenitude principle' according to which all logically possible mathematical objects exist (Balaguer, 1998b, p. 5) ${ }^{39}$ In order to account for the wide-spread intuition that the truth of statements like ' $2+2=4$ ' is in some sense absolute and does not simply follow from the consistency of the Peano axioms, Balaguer draws a distinction between 'truth in a structure' and 'truth simpliciter'. A mathematical proposition $m$ is true in a structure iff there is a consistent set of axioms defining a structure

\footnotetext{
${ }^{38}$ It is important to note that Hamkins' pluralism does not undermine the status of set theory as a foundation for mathematics, since all familiar mathematical objects and structures (for example, those of the natural or real numbers) exist in all of the sub-universes of the set-theoretic multiverse. What set theorists like Hamkins want to point out is that it does not seem plausible to assume that there is 'a unique absolute background concept of set, whose set-theoretic truths are immutable' (Hamkins, 2012, p. 417), and consequently, that it is not the case that there are uniquely true or false answers to open questions like $\mathrm{CH}$.

${ }^{39}$ I take the main difference between Balaguer's and Hamkins' views to be a metaphysical focus on hierarchies of sets as foundational in Hamkins' case, and viewing all possible mathematical objects as metaphysically on par in Balaguer's case. Hamkins argues that there are different universes corresponding to different notions of set theory one could create/describe from one another by the method of forcing. All other mathematical structures reduce to set theory à la Bourbaki, so that there are different copies of, for example, the natural numbers within each of these different universes of sets; see section 5 of Hamkins (2012). A further difference is that Hamkins is committed to there not being a definite answer to $\mathrm{CH}$, whereas Balaguer allows for the possibility that mathematicians will at some point agree on a 'standard model' for set theory (Balaguer, 1998b, p. 64).
} 
in which $m$ is true. A mathematical proposition $m$ is true simpliciter iff there is an intended structure (a 'standard model') of the given branch of mathematics and $m$ is true in the standard model. For example, the standard model of arithmetic are the natural numbers, and since statements like ' $2+2=4$ ' are true in the general structure of arithmetic as well as in the particular structure of the natural numbers, ' $2+2=4$ ' is true simpliciter. However, not every mathematical realm has a standard model. That is, for some parts of the mathematical realm, it is not the case that our full conception of the objects in question is precise enough to zero in on a unique structure. In those parts of the mathematical universe, the concept of 'true simpliciter' simply doesn't apply. In set theory, for example, there are first-order structures in which $\mathrm{CH}$ turns out true and some in which it turns out false. However, it might be the case that our conception of 'set' is not precise enough to pick out a unique structure in which $\mathrm{CH}$ is determinately true or false ${ }^{40}$ If so, then neither those parts of the mathematical realm that instantiate structures in which $\mathrm{CH}$ is true, nor those parts of the mathematical realm that instantiate structures in which $\mathrm{CH}$ is false are metaphysically privileged.

Besides offering an attractive way to deal with disagreements about open questions in mathematics, pluralism is plausible for two independent reasons. The first one is that it accurately reflects mathematical practice. For example, it is a fact that set theorists explore different set theoretic universes that correspond to different conceptions of 'set.' True, a majority work within ZFC, and consequently, in a universe characterised by the notion of set implicit in ZFC. However, as laid out above, there are also those like Aczel, who work with a notion of set that doesn't conform to ZFC. Similarly, there are those (like Woodin) whose mathematical work reflects a pre-theoretic commitment to a set-theoretic universe that determinately

\footnotetext{
${ }^{40}$ Balaguer leaves it open whether this is the case, i.e. he leaves open the possibility that set theorists will at some point be able to agree on a standard model for set theory; (Balaguer, 1998b, p. 64). See previous footnote.
} 
verifies or falsifies $\mathrm{CH}$, and those (like Todorcevic, Moore, and Hamkins) whose work does not reflect such a commitment. It is also a fact, as laid out earlier, that some mathematicians are more interested in the constructive realms of mathematical reality, while others prefer working in the realms characterised by the laws of classical logic.

A second reason why pluralism is plausible independently of the problem of disagreement is that it solves the two most notorious problems for realism about mathematics: the problem of epistemic acces: ${ }^{41}$ and the problem of reductive uniqueness ${ }^{42}$ It solves the former by assuming the existence of all logically possible mathematical objects, so that knowing a mathematical proposition $m$ becomes equivalent to knowing that $m$ is consistent (relative to one's background theory) ${ }^{43}$ It solves the latter by embracing reductive non-uniqueness, i.e. by rejecting the idea that our mathematical theories describe unique collections of objects ${ }^{44}$

\footnotetext{
${ }^{41}$ The 'access problem' for mathematical realism, first formulated by Benacerraf (1973) and later refined by Field (1989), points out the seeming impossibility to account for the striking coincidence between our mathematical beliefs and the mathematical truths. According to Benacerraf 'If... numbers are the kinds of entities they are normally taken to be [namely, mind-independent abstract objects], then the connection between the truth conditions for the statements of number theory and any relevant events connected with the people who are supposed to have mathematical knowledge cannot be made out' (Benacerraf, 1973, p. 673). Field clarifies: 'Benacerraf's challenge... is to provide an account of the mechanisms that explain how our beliefs about these remote entities can so well reflect the facts about them... The idea is that if it appears in principle impossible to explain this, then that tends to undermine the belief in mathematical entities, despite whatever reason we might have for believing in them' (Field, 1989, p. 26).

${ }^{42}$ Thanks to the work of the Bourbaki group, we know that set theory is a foundation for mathematics. The problem of reductive uniqueness, also first formulated by Benacerraf, arises because this foundation suffers from an indeterminacy problem. The number three, for example, can be expressed as $\{\{\{\emptyset\}\}\}$ (as suggested by Ernst Zermelo) or as $\{\emptyset,\{\emptyset\},\{\emptyset,\{\emptyset\}\}\}$ (as suggested by John von Neumann). These two characterisations are not equivalent: von Neumann's reduction implies that the number one is a member of the number three, whereas Zermelo's reduction implies nothing of the sort.

${ }^{43}$ One might worry here that this does not explain how human beings arrive at knowledge of consistency, but the pluralist can respond that this issue is both irrelevant to the question of realism, and that it arises not only for pluralists, but for everyone else, too; cf. Balaguer (1998b, pp. 69-75).

${ }^{44}$ One might worry that, if we want to avoid the objection from reference failure, the use of singular terms in mathematical theories must be taken to imply unique referents. To this the pluralist can respond that embracing reductive non-uniqueness is precisely to deny that mathematical singular terms must have unique referents (and that the antirealist has to provide additional argument to establish that the use of mathematical singular terms is acceptable only if there are unique referents for such terms; cf. Balaguer (1998b, pp. 84-91).
} 
It is certainly unorthodox to try to reconcile mathematical realism with the idea of a plurality of mutually exclusive mathematical (sub-)universes, but given that mathematical entities are non-spatial and non-temporal, there is no danger that they might 'crowd each other out.' Contrary to an often-stated objection, a pluralist view of mathematics is also not contradictory. The fact that both $\mathrm{ZFC}+\mathrm{CH}$ and $\mathrm{ZFC}+\neg \mathrm{CH}$ truly describe parts of mathematical reality does not entail that ZFC $+\mathrm{CH}$ and $\mathrm{ZFC}+\neg \mathrm{CH}$ are true in the same part. It also doesn't mean that 'ZFC + $\mathrm{CH}$ ' and 'ZFC $+\neg \mathrm{CH}$ ' are both absolutely true (remember the distinction between 'true in a structure' and 'true in the standard model'). 'ZFC $+\mathrm{CH}$ ' and 'ZFC $+\neg \mathrm{CH}$ ' simply describe different parts of the mathematical realm that instantiate slightly different concepts of set, some nested in others or less inclusive than others (Balaguer, 1998b, p. 59).

\subsection{Meta-ethical relevance}

In section 3 of this paper, I discussed three recent arguments for moral realism that rely on the premise (a) that there exists fundamental mathematical disagreement, plus on one further premise each. These additional premises are (b) that mathematical realism implies the view that disagreements between two subjects $\mathrm{A}$ and B about a mathematical proposition $m$ suggest that either A or B (or both) must be mistaken (section 3.1); (c) that fundamental disagreement between conceptually competent people over a mathematical proposition $m$ is incompatible with an a priori justification of belief in $m$ (section 3.2.); and (d) that mathematical disagreements are evidence that the mathematical truths could be very different from what we believe them to be (section 3.3).

It should be clear by now that if mathematical pluralism is a coherent option for the mathematical realist, (b), (c), and (d) are false. It is not the case, as stated by (b), that realism about mathematics requires us to explain mathematical disagree- 
ment with cognitive shortcomings or mistakes of some sort-disagreements might simply reflect differences in mathematical interest. It is also not the case, as stated by (c), that belief in propositions over which mathematicians disagree cannot be a priori justified. It is true, on a pluralist view, that whether a mathematical proposition $m$ appears self-evident to a subject $S$ depends on the mathematical tastes and interests of $S$. However, justification is not contingent upon self-evidence. Rather, every consistent mathematical proposition $m$ is a priori justified given its consistency. Hence, a priori justification does no longer depend on the blurry notion of self-evidence, but is grounded in the much clearer ${ }^{45}$ notion of consistency. Finally, it is not the case, as stated by (d), that mathematical disagreements are evidence that the mathematical truths could be very different from what we believe them to be. On a pluralist picture, for every belief $B$ in a consistent mathematical proposition $m$ there is a corresponding mathematical truth $t$ that renders $B$ true.

Note that we do not need to demonstrate that mathematical pluralism is true in order to show that (b), (c), and (d) are false. It is enough to demonstrate that pluralism is a genuine possibility for mathematical realists; (b), (c), and (d) are false even if mathematical pluralism is only a coherent option. On the other hand, in order to refute my claim that mathematical realists can accommodate mathematical disagreements, one would have to show that mathematical pluralisma view that reflects mathematical practice so well-is definitely false, or at least highly implausible. A tall order.

The upshot of my argument is that what I called the 'Standard View' of mathematical and moral realism at the beginning of my paper, i.e. the view that mathematical realists have a much better case than moral realists regarding the problem of disagreement, is correct after all. However, the reason it is correct is not because there are no disagreements in mathematics, but because mathematical realism is

\footnotetext{
${ }^{45}$ If not entirely clear; cf. (Balaguer, $1998 \mathrm{~b}$, Ch. 3.5).
} 
compatible with mathematical disagreement.

\section{$5 \quad$ Potential objections}

\subsection{Why is pluralism no option for moral realists?}

Why should it not be possible for moral realists to deflect the problem of disagreement by endorsing a pluralist position analogous to the mathematical one? After all, any sensible form of moral realism should be able to accommodate a significant degree of diversity of opinion and perhaps also indeterminacy in the absence of sufficient information. Which features of moral realism, if any, prevent a pluralist resolution of fundamental disagreements?

Let me begin my response to this objection by listing some of the essential conditions that must be met for a moral position to be legitimately called 'realism. ${ }^{46}$ The first condition is that first-order moral statements, such as 'We have a pro tanto obligation to avoid causing other beings harm,' must be considered truth-apt, with at least some such statements qualifying as non-vacuously true. This condition, which Gideon Rosen calls 'minimal realism' (Rosen, 1994, p. 281), rules out noncognitivist, expressivist, and error-theoretic theories of moral discourse. But this is not a sufficient characterisation for many moral realists. In addition, they believe in the objectivity or 'response-independence' of moral truths, such that whether or not a given normative judgement applies to a given action neither depends on the attitudes of the observers judging the action, nor on the attitudes of the agent whose action is being judged ${ }^{47}$ This condition rules out all moral theories relativising the truth of moral statements to contexts of assessment. Finally, non-naturalist

\footnotetext{
${ }^{46}$ Some moral realists endorse a realist position not only about moral judgements, but about all normative judgements. Enoch, for example, calls his position 'meta-normative realism' and argues that moral facts are a subset of normative facts, and that many of the questions traditionally thought to be about morality are really (meta-)normative questions (Enoch, 2011, pp. 1-8).

${ }^{47}$ Cf., for example, Svavarsdóttir (1999, p. 162)
} 
'robust' moral realists are ontologically committed to moral truths irreducible to truths about a non-moral subject matter, such as empirical truths about nature ${ }^{48}$ More naturalistically inclined moral realists, such as the 'Cornell Realists,' believe that moral truths can be reduced to 'natural' truths ${ }^{49}$ However, in order to explain why realist moral pluralism is incoherent, the distinction between naturalist and non-naturalist moral realism does not matter.

Now, it is not enough to simply assert that moral realism thus understood is incompatible with a pluralist view - according to which a moral statement uttered in a given (fixed) context can have more than one truth-value in different 'moral universes'-because on a monist realist picture each and every moral proposition must have exactly one unique truth-value. This would beg the question against the pluralist.

However, there is a non-question-begging explanation for why moral realist pluralism is incoherent. Assume that Peter and Mary are discussing the issue of capital punishment. Peter believes that the appropriate punishment for murdering people for pleasure is death. Mary disagrees; she thinks the appropriate punishment for such a crime is life imprisonment. Now, a moral realist would of course not deny that different people can have different opinions on the matter. She would not even deny that there may be legitimate reasons to see the matter one way, and legitimate reasons to see it another. For example, a murder victim's mother may have legitimate reasons to prefer capital punishment over life imprisonment for her child's murderer, and a human rights activist may have legitimate reasons to prefer life imprisonment over capital punishment. Nevertheless, moral realists believe that, all else being equal, i.e. assuming there is no change in relevant context, the statement 'The appropriate punishment for murdering people for pleasure is life imprisonment'

\footnotetext{
${ }^{48}$ Examples for non-naturalist moral realists include Enoch (2011); Nagel (1986, 1997); Parfit (2011); Scanlon (1998); Shafer-Landau (2003); Wedgwood (2007).

${ }^{49}$ Examples of naturalist moral realists include Bloomfield (2001); Boyd (1988); Brink (1989); Sturgeon (1984).
} 
has a single, determinate truth-value. Of course it may be difficult to figure out the correct truth-value, and of course there may be good reasons why people hold different opinions on the matter, but none of this changes the fact that, according to moral realism, first-order moral statements are either true or false $\longdiv { 5 0 }$

Assume, for reductio, that pluralism and moral realism were compatible, such that a statement like 'The appropriate punishment for murdering people for pleasure is life imprisonment' could be true in some 'moral universes' and false in others. Is there a way of spelling out what a 'moral universe' might be that offers a sustainable version of moral pluralism, but that doesn't collapse into a view that no longer fulfils the conditions for realism laid out above? I don't believe there is.

One could argue that a 'moral universe' is constituted by the totality of norms and values of a particular culture or religion, or of a particular linguistic community, or those arising out of the set of my unique, personal, subjective experiences, asf. And since there are many different cultures, religions, linguistic communities, etc., there are arguably many 'moral universes', in some of which a statement like 'The appropriate punishment for murdering people for pleasure is life imprisonment' may be true, and in some of which it may be false. However, this way of characterising a 'moral universe' clearly relativises the truth of moral statements to contexts of assessment, the contexts being the culturally, religiously etc. formed attitudes of observers and agents. And this is precisely the kind of relativisation moral realists reject.

But perhaps this was the wrong way of characterising a 'moral universe in the first place;' perhaps 'moral universes' are better characterised as maximally consistent sets of truth-makers for moral statements. However, the truth-makers of moral statements, according to moral realists, are objective, response-independent moral

\footnotetext{
${ }^{50}$ See also Berry $(2018$, §3) for a related argument that moral realists can't avail themselves of pluralist moves analogous to those of mathematical realists in order to solve problems of epistemic access.
} 
facts (which can be spelled out in naturalist or non-naturalist terms), and no matter how we characterise maximally consistent sets of truth-makers for moral statements, moral realism entails that only one such set is the 'correct' one, i.e. the one providing the correct truth-value for each and every possible moral statement. Hence, also this way of cashing out the notion of a 'moral universe' does not lead us to a sustainable version of realist moral pluralism.

Setting aside talk of 'moral universes', there is another reason to reject the notion of moral pluralism. To see why, consider the idea, popular among meta-ethicists both of the realist $t^{51}$ and the antirealist ${ }^{52}$ camp, that the key function of moral discourse is to expedite cooperative behaviour:

There is a rather obvious pragmatic/evolutionary advantage of humans having a moral outlook... Because of the importance of certain patterns of behaviour (and emotional responses), one would expect that humans, capable of complex coordinative behaviour, would evolve more or less shared normative systems that have the sorts of features characteristic of a typical moral outlook. In short, given what human beings are like, the setting in which they find themselves, and that they are capable of quite sophisticated coordinative behaviour, one would expect them to develop strategies that would most effectively solve problems of coordination crucial for group survival. (Timmons, 1999, p. 158)

The unacceptability of moral pluralism falls out of this function. Since we use moral discourse to decide how to act in a given situation, we cannot accept a plurality of mutually exclusive moral systems: unresolved inconsistencies would frustrate the function of the discourse. Consider an action A (for example, executing a mass murderer). Holding relevant contexts fixed, a moral realist is committed to saying

\footnotetext{
${ }^{51}$ Cf., for example, Clarke-Doane (2012); Enoch $(2010)$.

${ }^{52}$ Cf., for example, Street (1994); Joyce (2007).
} 
that $\mathrm{A}$ is either permissible or impermissible. A position in which $\mathrm{A}$ can sometimes be permissible and sometimes not is no longer a realist position. Analogously, no mathematical position that would allow different truth values for a mathematical proposition about the intended structures of the mathematical universe (for example, the natural numbers) would count as a realist position. The actual world (and our actions in it) are the moral analogue to the intended structures of mathematical realism. The difference between mathematical and moral disagreement is thus that moral disagreements occur within the 'intended structure' of ethics, i.e. our actual world, whereas mathematical disagreements occur outside of established intended structures of mathematics. This explains why embracing pluralism is possible for the mathematical realist, but not for the moral realist.

\subsection{Pluralism does not resolve fundamental disagreements}

A second objection against the claim that mathematical and moral disagreement are relevantly disanalogous might be that there seems to be a tension between the arguments for the existence of fundamental disagreements given at the beginning of this paper, and the arguments for mathematical pluralism given at the end of this paper. After all, the former seem to suggest that mathematicians disagree over the acceptability of different logics and new axioms for set theory in a way that resists pluralist resolution. In the case of logic, for example, some radical intuitionists believe that classical logicians don't even have a cogent object of study. Similarly, in the case of set theory, we seem to have a deep disagreement between those who believe in the existence of a single intended set-theoretic universe $\mathrm{V}$, which any new axioms must attempt to describe, and those who do not. One might argue that it doesn't seem right to say that those disagreements can be comfortably handled by a pluralist approach, at the core of which is the idea that all consistent formal systems are legitimate objects of mathematical study. 
This objection can be answered as follows. It is true that, despite the coherence of logical and set-theoretic pluralism, not everyone endorses a pluralistic position. Monism is still the preferred position for some, perhaps even many, logicians and mathematicians, and monists are by default opposed to pluralistic resolutions of disagreements. But that is beside the point. In order to demonstrate that mathematical and moral disagreement are disanalogous in a way that is relevant to the meta-ethical arguments discussed, all we need to show is that mathematical pluralism is a coherent possibility, whereas an analogous moral pluralism is not. The former has been demonstrated in section 4, the latter in section 5.1.

\subsection{Pluralism reduces fundamental disagreements to merely verbal disagreements}

A third possible objection might be that, on a pluralist picture, the fundamental disagreements in question turn out to be merely verbal. Pluralists like Balaguer and Hamkins, the objection goes, do not mean to say that mathematicians can disagree over the truth-value of a mathematical proposition like $\mathrm{CH}$ without one of them being wrong. Rather, they mean to say that mathematicians can use the sentence ' $\mathrm{CH}$ ' in multiple, equally legitimate ways, yet whenever the notion of set implied in the different usages of ' $\mathrm{CH}$ ' varies, ' $\mathrm{CH}$ ' actually expresses different propositions. Consequently, set-theorists who claim that $\mathrm{CH}$ is true and set-theorists who claim that $\mathrm{CH}$ is false are actually talking about different things.

Here is a quick answer to this objection. Perhaps all pluralists are covert Tarskians who believe that truth is a property of sentences. If so, then the question whether ' $\mathrm{CH}$ ' actually expresses the same proposition in every part of the settheoretic multiverse doesn't even arise. ' $\mathrm{CH}$ ' is the same sentence in every part of the pluralistic mathematical cosmos. Assuming that all there is to say about truth is 
contained in the schema " $\mathrm{P}$ ' is true if and only if $\mathrm{P}$ ', it is clear that the disagreement between set-theorists who claim that $\mathrm{CH}$ is true and set-theorists who claim that $\mathrm{CH}$ is false is not merely verbal, but as substantial as can be.

However, even though this move deflects the objection from verbal disagreement, I don't think that such a deflationary move is necessary. The objection from verbal disagreement reduces mathematical pluralism to the trivial position that people talking about different things cannot be disagreeing. But this interpretation is unjustified and misses the substantiality of the pluralist thesis. Let's look at two quotes from Balaguer and Hamkins for illustration:

According to [full-blooded Platonists], ZFC does not describe a unique universe of sets; it describes many different universes of sets. For example, it describes some universes in which the continuum hypothesis $(\mathrm{CH})$ is true and others in which it is not true. This is simply because $\mathrm{ZFC}+\mathrm{CH}$ and $\mathrm{ZFC}+\neg \mathrm{CH}$ are both consistent and, hence, both truly describe parts of the mathematical realm. (Balaguer, 1998b, p. 59)

On the multiverse view... the continuum hypothesis is a settled question; it is incorrect to describe the $\mathrm{CH}$ as an open problem. The answer to $\mathrm{CH}$ consists of the expansive, detailed knowledge set theorists have gained about the extent to which it holds and fails in the multiverse, about how to achieve it or its negation in combination with other diverse settheoretic properties... the most important and essential facts about $\mathrm{CH}$ are deeply understood, and these facts constitute the answer to the $\mathrm{CH}$ question. (Hamkins, 2012 , p. 429)

Both Balaguer's and Hamkins' ways of referring to 'the' Continuum Hypothesis suggest that, on their view, there is a single Continuum Hypothesis, arising on the 
background of ZFC, whose truth-value can vary across different realms of the pluralistic mathematical cosmos/ the multiverse. True, the concept of set instantiated in these different realms can vary, but this variance is not enough to establish the non-identity of $\mathrm{CH}$ in those different realms. There is a shared meaning to ' $\mathrm{CH}$ ' in $\mathrm{CH}$-universes and $\neg \mathrm{CH}$-universes that is substantial enough to preclude a change of topic.

Consider the disagreement between a set-theoretic pluralist and a set-theoretic monist. The former believes that $\mathrm{CH}$ is true in some set-theoretic universes and false in others. The latter believes $\mathrm{CH}$ is determinately true or false in the one genuine V. This situation does not imply that ' $\mathrm{CH}$ ' means something different for them. If it did, they would not be in disagreement, which they most certainly are: thinking of mathematical reality as a universe has different implications than thinking of it as a multiverse. Their disagreement is precisely over which of the two conceptions correctly describes mathematical reality; their disagreement is not over what the meaning of ' $\mathrm{CH}$ ' is.

The point becomes even clearer when we look at the case of set theory more generally. Surely subtle differences in the way we interpret 'set' must be possible without this constituting a change of topic. If we had no such 'conceptual leeway,' it would be very difficult to consider different possible precisifications of the concept in a coherent manner. For example, rather than saying that ZFC constitutes an improvement of naïve set theory, we would have to say that they are something totally different, which is very implausible. We also wouldn't say that mathematicians working with different set-theoretic models (e.g. the constructible universe L, its forcing extensions $\mathrm{L}[\mathrm{G}]$, the class of hereditarily ordinal definable sets HOD, etc.) aren't all investigating the same things, namely sets, even though each of these models implies a slightly different concept of set. Rather, what we might say is that every model instantiates an admissible 'precisification' of our pre-theoretic notion of 
set, each of which purports to incorporate the core features involved in the use of "is a member of' or 'contains'; however, none of these precisifications is more correct, or in some sense metaphysically special, such that it can supersede the others.

This is not to suggest that the question how far can we change our concepts while still talking about the same thing isn't an important and intricate one; it absolutely is. It may even be a question that concerns pluralists more than it concerns monists. Yet it is a separate problem from the one tackled in this paper, namely, the coherence of mathematical pluralism as a meta-ethically relevant disanalogy between mathematical and moral disagreement.

\section{Conclusion: Mathematical and moral disagree- ment}

In this paper, I have argued that the possibility of adopting a pluralist view of mathematics offers a way to accommodate fundamental mathematical disagreements within a realist view of mathematics; that an analogous route is not open to the moral realist; and that this has direct consequences for recent meta-ethical arguments using a premise from mathematical disagreement to argue for moral realism.

But of course, this does not mean that there are no more questions to ask about mathematical pluralism. For example, one might be interested to hear more about how reference to mathematical objects works on a pluralist picture Colyvan and Zalta, 1999), or how the plenitude principle Balaguer invokes can be coherently formulated (Restall, 2003), or perhaps why the conceptual resources that account for our ability to categorically grasp the intended structure of arithmetic (i.e. the natural numbers) don't also let us categorically pin down a model of the reals. ${ }^{53}$ I am not denying that mathematical pluralists have more work to do. My point is

\footnotetext{
${ }^{53}$ I owe this point to Sharon Berry.
} 
simply that accounts like Hamkins's and Balaguer's demonstrate the in principle possibility of being a mathematical realist and a mathematical pluralist at the same time, which dissolves apparently first-order mathematical disagreements into disagreements about which parts of mathematical reality are most interesting to study. I have further argued that an analogous position is not open to the moral realist: the moral universe cannot branch out into different, mutually exclusive sub-universes because moral judgements are always indexed to the actual world. Mathematical and moral disagreement are thus not as straightforwardly analogous as recent metaethical arguments for moral realism present it.

I also do not claim to have presented the first argument explaining why 'companions-in-guilt' arguments for mathematics and ethics are flawed. Hallvard Lillehammer (2007) argues that mathematical standards of rule-following are capable of generating determinate answers to particular questions in a way that ethical standards are not. Jonathan Lear $(1983)$ and A.W. Moore (2013) emphasise that mathematics and ethics are disanalogous with respect to their applicability to the physical world: the mathematical truth that a plane cannot be divided up into a number of pentagons corresponds to the physical truth that it is impossible to tile my bathroom floor with pentagonal tiles. This is because - some - mathematical statements describe abstract structures that preserve certain structural features found in the physical world, which is why mathematics finds application in physics. Nothing similar can be said about ethical statements.

Nevertheless, the argument I have presented here is more than an addition to the list of disanalogies between mathematics and ethics, and also more than a simple refutation of arguments for moral realism. Its goal is to highlight to what extent antirealist objections from disagreement depend on a thoroughly analogous interpretation of the kinds of disagreement in question, and to show why such an analogous interpretation is impossible for the analogy between mathematical and 
moral disagreement. The paper further encourages a more critical engagement with the metaphysical implications of disagreement for realist positions about a priori domains. It is intended to contribute to a better understanding of the nature of disagreements within a priori domains like mathematics, and it suggests that a better understanding of these issues can open up new ways of understanding the realismantirealism debates about such domains.

Munich Center for Mathematical Philosophy (MCMP), Ludwig-MaximiliansUniversity Munich, Germany 


\section{References}

Aczel, P. (1988). Non-well-founded sets. Center for the Study of Language and Information, Lecture Notes 14 .

Balaguer, M. (1995). A Platonist epistemology. Synthese 103, 303-325.

Balaguer, M. (1998a). Non-uniqueness as a non-problem. Philosophia Mathematica 6, 63-84.

Balaguer, M. (1998b). Platonism and Anti-Platonism in Mathematics. Oxford University Press.

Benacerraf, P. (1965). What numbers could not be. The Philosophical Review 74(1), 47-73.

Benacerraf, P. (1973). Mathematical truth. The Journal of Philosophy 70(19), 661-679.

Berry, S. (2018). (Probably) not companions in guilt. Philosophical Studies 175(9), 2285-2308.

Bishop, E. (1967). Foundations of Constructive Analysis. McGraw-Hill.

Bloomfield, P. (2001). Moral Reality. Oxford University Press.

Boolos, G. (1971). The iterative conception of set. The Journal of Philosophy 68(8).

Boyd, R. N. (1988). How to be a moral realist. In G. Sayre-McCord (Ed.), Essays on Moral Realism, pp. 181-228. Cornell University Press.

Brink, D. O. (1989). Moral Realism and the Foundations of Ethics. Cambridge University Press.

Brouwer, L. (1967). On the domains of definition of functions (1927). In J. V. Heijenoort (Ed.), From Frege to Gödel. A Source Book in Mathematical Logic, 1879-1931, pp. 446-463. Harvard University Press.

Burgess, J. (2007). Against ethics. Ethical Theory and Moral Practice 10.

Clarke-Doane, J. (2012). Morality and mathematics: The evolutionary challenge. Ethics 122(2), 313-340.

Clarke-Doane, J. (2014). Moral epistemology: The mathematics analogy. Noûs 48(2), 238-255.

Cohen, P. (1963). The independence of the Continuum Hypothesis. Proceedings of the National Academy of Sciences of the United States of America 50(6), 1143-1148.

Colyvan, M. (2001). The Indispensability of Mathematics. Oxford University Press.

Colyvan, M. and E. Zalta (1999). Mathematics: Truth and fiction? Philosophia Mathematica 7(3), $336-349$.

Enoch, D. (2009). How is moral disagreement a problem for realism? Journal of Ethics 13, 15-50.

Enoch, D. (2010). The epistemological challenge to metanormative realism: How best to understand it, and how to cope with it. Philosophical Studies 148, 413-438.

Enoch, D. (2011). Taking Morality Seriously: A Defense of Robust Realism. Oxford University Press.

Feferman, S., H. Friedman, P. Maddy, and J. Steel (2000). Does mathematics need new axioms? The Bulletin of Symbolic Logic 6(4). 
Field, H. (1980). Science without Numbers. Oxford University Press.

Field, H. (1989). Realism, Mathematics, and Modality. Blackwell Publishing.

Foreman, M. D., M. Magidor, and S. Shelah (1988). Martin's maximum, saturated ideals, and non-regular ultrafilters. Part I. Annals of Mathematics Second Series 127(1), 1-47.

Fraenkel, A., Y. Bar-Hillel, and A. Levy (1973). Foundations of Set Theory (2 ed.). North Holland.

Gewirth, A. (1988). Is cultural pluralism relevant to moral knowledge? Social Philosophy and Policy 11, 22-42.

Goldman, A. (1967). A causal theory of knowing. The Journal of Philosophy 64(12), 357-372.

Gowans, C. (2000). Moral Disagreements: Classic and Contemporary Readings. Routledge.

Gödel, K. (1938). The consistency of the axiom of choice and of the Generalized Continuumhypothesis. Proceedings of the National Academy of Sciences of the United States of America $24(12), 556-557$.

Hamkins, J. D. (2012). The set-theoretic multiverse. The Review of Symbolic Logic 5(3), 416-449.

Harman, G. (1977). The Nature of Morality: An Introduction to Ethics. Oxford University Press.

Hellman, G. (1989). Never say 'never'! on the communication problem between intuitionism and classicism. Philosophical Topics 17, 47-67.

Hellman, G. and J. Bell (2006). Pluralism and the foundations of mathematics. In S. Kellert, H. Longino, and K. Waters (Eds.), Scientific Pluralism. Minnesota Studies in the Philosophy of Science, pp. 64-79. University of Minnesota Press.

Joyce, R. (2007). The Evolution of Morality. MIT Press.

Lear, J. (1983). Ethics, mathematics and relativism. Mind 92(365), 38-60.

Leiter, B. (2009). Moral skepticism and moral disagreement in Nietzsche. Public Law and Legal Theory Working Papers $25 \%$.

Lewis, D. (1986). On the Plurality of Worlds. Blackwell Publishing.

Lillehammer, H. (2007). Companions in Guilt: Arguments for Ethical Objectivity. Palgrave Macmillan.

Linnebo, Ø. and S. Shapiro (2019). Actual and potential infinity. Nô̂s 53(1), 160-191.

Loeb, D. (1998). Moral realism and the argument from disagreement. Philosophical Studies 90, 281-303.

Mackie, J. (1977). Inventing Right and Wrong. Penguin.

Maddy, P. (1996). The legacy of mathematical truth. In A. Morton and S. Stich (Eds.), Benacerraf and his Critics, pp. 60-72. Blackwell.

Moore, J. (2013). Forcing axioms and the Continuum Hypothesis. Part ii: Transcending $\omega 1-$ sequences of real numbers. Acta Mathematica 210(1), 173-183.

Nagel, T. (1986). The View from Nowhere. Oxford University Press. 
Nagel, T. (1997). The Last Word. Oxford University Press.

Nussbaum, M. (1993). Non-relative virtues: An Aristotelian approach. In M. Nussbaum and A. Sen (Eds.), The Quality of Life, pp. 242-269. Oxford University Press.

Parfit, D. (2011). On What Matters. Oxford University Press.

Putnam, H. (1975). Mathematics, Matter and Method. Cambridge University Press.

Quine, W. (1951). Two dogmas of empiricism. The Philosophical Review 60(1), 20-43.

Rawls, J. (1980). Kantian constructivism in moral theory. The Journal of Philosophy 77, 515-572.

Restall, G. (2003). Just what is full-blooded Platonism? Philosophia Mathematica 11 (1), 82-91.

Rieger, A. (2008). Paradox, ZF, and the axiom of foundation. In D. DeVidi, M. Hallett, and P. Clark (Eds.), Logic, Mathematics, Philosophy: Vintage Enthusiasms, pp. 171-188. Springer.

Rosen, G. (1994). Objectivity and modern idealism: What is the question? In M. Michael and J. O'Leary-Hawthorne (Eds.), Philosophy in Mind, pp. 277-314. Kluwer Academic.

Scanlon, T. (1998). What We Owe to Each Other. Harvard University Press.

Shafer-Landau, R. (1994). Ethical disagreement, ethical objectivism and moral indeterminacy. Philosophy and Phenomenological Research 54(2), 331-344.

Shafer-Landau, R. (2003). Moral Realism: A Defence. Oxford University Press.

Steiner, M. (1975). Mathematical Knowledge. Cornell University Press.

Street, S. (1994). A Darwinian dilemma for realist theories of value. Philosophical Studies 127(1), 109-166.

Sturgeon, N. (2006). Ethical naturalism. In D. Copp (Ed.), The Oxford Handbook of Ethical Theory, pp. 91-121. Oxford University Press.

Sturgeon, S. (1984). Moral explanations. In D. Copp and D. Zimmerman (Eds.), Morality, Reason, and Truth: New Essays on the Foundations of Ethics, pp. 49-78. Rowman \& Allanheld.

Svavarsdóttir, S. (1999). Moral cognitivism and motivation. The Philosophical Review 108, 161219.

Tersman, F. (2006). Moral Disagreement. Cambridge University Press.

Timmons, M. (1999). Morality Without Foundations. Oxford University Press.

Todorcevic, S. (2002). Generic absoluteness and the continuum. Mathematical Research Letters $9(4), 465-471$.

Todorcevic, S. (2018). Collapsing $\omega_{2}$ with semi-proper forcing. Archive for Mathematical Logic 57(1-2), 185-194.

Van Atten, M. (2006). Brouwer meets Husserl: On the Phenomenology of Choice Sequences. Springer.

Van Atten, M., D. Van Dalen, and R. Tieszen (2002). Brouwer and Weyl: The phenomenology and mathematics of the intuitive continuum. Philosophia Mathematica 10(2), 203-226. 
Wedgwood, R. (2007). The Nature of Normativity. Clarendon Press.

Weyl, H. (1994). The Continuum: A Critical Examination of the Foundation of Analysis (1918). Dover Publications.

Williams, B. (1985). Ethics and the Limits of Philosophy. Harvard University Press.

Wong, D. (1984). Moral Relativity. University of California Press.

Woodin, H. (2017). In search of ultimate-L: The 19th Midrasha Mathematical Lectures. The Bulletin of Symbolic Logic 23(1), 1-109. 